\title{
A resistência cotidiana infanto-juvenil durante a ditadura cívico- militar de Alfredo Stroessner no Paraguai (1954-1989)
}

The infant-juvenile everyday resistance during the civic-military dictatorship of Alfredo Stroessner in Paraguay (1954-1989)

Paulo Alves Pereira Júnior* paulopereira_pf@hotmail.com

Resumo: Entre os anos de 1954 e 1989, o Paraguai viveu sob a ditadura cívicomilitar de Alfredo Stroessner. Seu governo desenvolveu uma estrutura que reprimiu qualquer crítica realizada. As produções bibliográficas que analisam a forma de resistência a esse governo destacam as contestações partidárias e as ações das organizações armadas, "esquecendo-se" das práticas oposicionistas de certos atores sociais no âmbito privado. À vista disso, discorreremos sobre a resistência cotidiana desenvolvida pelas crianças e pelos adolescentes durante o regime de Stroessner.

Palavras-chave: Paraguai, Stronismo, resistência infanto-juvenil

Abstract: Between 1954 and 1989, Paraguay lived under the civic-military dictatorship of Alfredo Stroessner. This government has developed a system that repressed all criticism. The bibliography that analyzes the resistance to this government draws attention to the challenges of political parties and the actions of armed groups, "forgetting" of the opposition conducted by certain social actors in the private sector. Thus, we will discuss about everyday resistance developed by children and adolescents during the government of Stroessner.

Keywords: Paraguay, Stronism, Infant juvenile resistance 


\section{Introdução}

No ano de 1954, Alfredo Stroessner articulou uma quartelada contra o presidente Federico Chaves. Dias após o putsh, Tomás Romero Pereira assumiu o posto de presidente provisório e, em junho, Stroessner foi nomeado pelo Partido Colorado para disputar a presidência do Paraguai. Sendo o único candidato, foi "eleito" em 11 de julho. Desde então, manteve-se no poder ininterruptamente até 1989 , através de eleições fraudulentas. Em linhas gerais, a ditadura cívico-militar de Stroessner ${ }^{1}$ desenvolveu uma estrutura paternalista e clientelista e criou um sistema de repressão contra os grupos opositores ao regime (PEREIRA JÚNIOR, 2015, p. 26-27).

A partir da década de 1980 , as crises internas do Partido Colorado acentuaram-se, dividindo-o em duas alas: os "tradicionalistas", que se opuseram ao sistema stronista $^{2}$, e os "militantes", que apoiaram o governo vigente. Por conta dessa conjuntura, a estrutura política do regime enfraqueceu-se e deu margem para prováveis insurreições, o que de fato ocorreu em fevereiro de 1989. Um Golpe de Estado, liderado por Andrés Rodríguez e apoiado por grupos colorados e militares, depôs Stroessner. Rodríguez assumiu provisoriamente o governo e no mesmo ano foi eleito constitucionalmente, governando até 1993 (PEREIRA JÚNIOR, 2015, p. 33).Em sua gestão, iniciou uma abertura política realizada "de cima para baixo" e aplicou na agenda política o desejo democrático, medida realizada para atender os anseios de setores da sociedade paraguaia (SOTO et al., 2004, p. 140).

Em meados do decênio de 1990, um número expressivo de exilados políticos retornou ao Paraguai. Em parceria com advogados, estudantes, agricultores e líderes indígenas, esses degredados formaram movimentos sociais que tinham como escopo exigir justiça aos crimes cometidos pelos agentes estatais durante a ditadura stronista. Tais grupos exigiam reparações financeiras e históricas, a partir da emersão das memórias dos torturados ou desterrados e dos familiares de pessoas desaparecidas ou assassinadas pelo regime (GAUTO; TALAVERA, 2003, p. 82-83). As ações promovidas por diferentes parcelas da sociedade resultaram na criação da Comisión de Verdad y Justicia (CVJ) no ano de 2003, cujo objetivo central foi a investigação dos crimes durante o governo de Alfredo Stroessner.

O resultado dessa pesquisa foi entregue em agosto de 2008 aos Três Poderes. O Informe Final da CVJ contém cerca de nove mil testemunhos e divide-se em oito tomos. Seus objetivos eram o questionamento das condições políticas, econômicas, sociais e culturais que legitimaram o regime stronista e a revisão dos delitos cometidos por agentes estatais e paraestatais contra a população. Em seu mandato, Fernando Lugo (20082012) promoveu diversas políticas memorialísticas sobre a ditadura de Stroessner, com o objetivo de reparar historicamente as experiências traumáticas sofridas pelos atores sociais no passado. Após o fim da CVJ, foi criada, em 2009, a Dirección General de Verdad, Justicia y Reparación (DGVJR), dependente da Defensoría del Pueblo del Paraguay.

Este artigo pretende identificar a resistência cotidiana infanto-juvenil e a participação política desse grupo, a partir dos tomos III e V do Informe Final da CVJ. Em um primeiro momento, discutiremos as nossas matrizes teórico-metodológicas. Por fim, destacaremos as formas como a fonte perfilou as ações e as ex-

\footnotetext{
${ }^{1}$ BenjamínArditi, em Adiós a Stroessner: La reconstrucción de la politica en el Paraguay(1992), apresenta o governo de Alfredo Stroessner como um poder dominante na política e que contou com o apoio expressivo de uma parte da sociedade e das Forças Armadas. Deste modo, utilizaremos o conceito de "ditadura/regime cívico-militar".

${ }^{2}$ Adotaremos a expressão stronismo, comumente utilizada pelos pesquisadores paraguaios que estudam a ditadura de Stroessner.
} 
periências das crianças e dos adolescentes durante a ditadura de Alfredo Stroessner no Paraguai.

\section{Resistência, cotidiano e infância: perspectivas teóricas}

Em A invenção do cotidiano (1980), Michel de Certeau destaca que dentro do cotidiano, entendido como um espaço que preocupa os indivíduos e os oprime, desenvolvem-se as estratégias e as táticas. Como estratégia, Certeau (1980) afirma que ela é a ação calculadora:

(...) das relações de forças que se torna possivel a partir do momento em que um sujeito de querer e poder (uma empresa, um exército, uma cidade, uma instituição cientifica) pode ser isolado. (...) Gesto da modernidade cientifica, política ou militar (CERTEAU, 1998, p. 99).

Compreendendo as estratégias como atividades impostas por um grupo "dominante", Certeau elucida que as táticas dos grupos e dos sujeitos estão dentro de um local controlado e observado pelo "inimigo". Esse movimento de resistência aproveita as brechas desse sistema para traçar possíveis saídas. Nessa conjuntura, as fissuras se abrem frente a um poder totalizante, criando situações inesperadas. Além de atuarem dentro do "campo de visão" de uma força dominadora, as táticas se caracterizam por escaparem desse "local" vigiado. Prosseguindo, o autor entende a tática de diversas formas, como: 1) As vitórias do "fraco" sobre o mais "forte" (caracterizado como um poderoso, a violência sobre algo); 2) Os pequenos sucessos de distintos atores sociais; 3) As artes de dar golpes no campo de outros; 4) As simulações polimorfas (CERTEAU, 1998, p. 47). Utilizaremos os referenciais teórico- metodológicos propostos por Michel de Certeau para explorar caminhos para a nossa problemática inicial, sempre estimando as conjunturas do local onde foram produzidas tais perspectivas e as particularidades em torno de nossa fonte, levando em consideração as singularidades da sociedade que a produziu. $\mathrm{O}$ autor desenvolve o conceito de "resistência cotidiana"3 através de um olhar sociocultural e a partir das experiências dos indivíduos e dos grupos ao longo do tempo. Aplicando tais ideias à realidade paraguaia, podemos entender as estratégias como instrumentos de controle desenvolvidos pelos mecanismos de repressão controlados pelo governo autoritário de Stroessner. Em compensação, compreendemos como táticas as ações contrárias ao modelo opressivo, desenvolvidas por determinadas parcelas da população de forma "indireta", atuando "dentro do campo de visão do inimigo".

Apesar disso, o conceito abre outras possibilidades, quando introduzido no caso específico do Paraguai. A atuação das guerrilhas armadas que lutaram contra a gestão de Stroessner caracteriza-se como estratégia, pois era formada por forças proporcionadas pelo isolamento de um grupo de querer e poder (geralmente ligado a um partido político), gerando distintas relações exteriores (com os camponeses, por exemplo) e visando atingir um alvo ou uma ameaça externa (o governo ditatorial). Em nossas análises, aplicaremos o conceito de tática/"resistência cotidiana" apenas às atividades articuladas pelas crianças e pelos adolescentes que se apropriaram dos "jogos" desenvolvidos pelas estruturas ditatoriais ao criarem saídas de um espaço vigiado e controlado pelos órgãos repressores. ${ }^{4}$

\footnotetext{
${ }^{3}$ O termo "resistência cotidiana" não é utilizado por Certeau em sua obra. Entretanto, uma vez que o autor pensa a renitência a parir do âmbito do cotidiano, não vemos nenhum empecilho para a utilização do presente término.

${ }^{4} \mathrm{O}$ governo de Stroessner sistematizou um mecanismo repressivo através de órgãos estatais como o Departamento de Investigaciones e a Dirección Nacional de Asuntos Técnicos (La Técnica). Esse modelo ultrapassou os muros das delegacias e dos quartéis militares e adentrou-se nos lares, nos locais de trabalho, nas universidades etc. Isso foi possível por conta da atuação dos pyragues(delatores da ditadura) na sociedade paraguaia. Tal estrutura - que controlava e vigiava diversos espaços sociais - desbaratou movimentos armados, desfez tentativas de derrubar o regime, perseguiu milhares de indivíduos, censurou veículos de comunicação e desarticulou ações opositoras político-partidárias e sindicais.
} 
Os marcos teóricos propostos por Certeau foram utilizados em diversos estudos sobre a participação infanto-juvenil na sociedade. Monica P. Ochoa, Paulina C. Ibarra e Ana V. Del Solar afirmam que a noção de tática permite articular uma referência compreensiva em que “(...)las prácticas de resistencia cotidianas de niños y niñas no quedan atrapadas ni en una visión aproblemática ni en una mirada patologizante de la conducta infantil"' (PEÑA OCHOA et al.,2014, p. 115). Tal perspectiva desnaturaliza os lugares socialmente atribuídos às crianças e aos adultos (PEÑA OCHOA et al., 2014, p. 115). Castillo-Gallardo e GonzálezCelisafirmam que os jovens refletem, constroem sua subjetividade e elaboram seu contexto social de forma particular, produzindo significados, culturas e, também, táticas políticas de resistência (CASTILLOGALLARDO; GONZÁLEZ-CELIS, 2015, p. 909-910).

Outros estudos acadêmicos evidenciam o papel político e social das crianças e dos adolescentes. Walter Benjamin destaca a importância do setor infanto-juvenil na sociedade ao elucidar que “(...) as crianças são inclinadas de modo especial a procurar todo e qualquer lugar de trabalho onde visivelmente transcorre a atividade sobre as coisas" (BENJAMIN, 1987, p.18). A atuação no campo da construção e do trabalho faz com que elas formem “(...) para si seu mundo de coisas, um pequeno no grande (...)" (BENJAMIN, 1987, p. 19). Peter L. Berger e Thomas Luckmann deslindam que a sociedade apresenta aos indivíduos prestes à socialização uma série predefinida de significantes. A socialização primária desenvolve-se na família e leva em consideração elementos emocionais. Já a socialização secundária articula-se em determinadas instituições, como a escola e a igreja, por exemplo.

Em tal situação, “(...) embora a criança não seja apenas passiva no processo da sua socialização, são os adultos que estabelecem as regras do jogo. A criança pode participar do jogo com entusiasmo ou com mal- humorada resistência" (BERGER; LUCKMANN, 2004, p. 142). Como não há uma estrutura paralela, a criança não tem escolha na seleção de significativos apresentados aos indivíduos no processo de socialização (BERGER; LUCKMANN, 2004, p. 142). Para Berger e Luckmann, o mundo da infância constitui-se em um modo que instala no indivíduo a confiança de que tudo "está bem" e representa o "mundo doméstico" (BERGER; LUCKMANN, 2004, p. 143-144).

Allison James e Alan Prout, ao elencarem as principais características da sociologia infantil, afirmam que a infância é uma construção social e um “(...) specific structural and cultural componente of many societies" (JAMES; PROUT, 1997, p. 08). Ademais, aclaram que as crianças não são atores passivos dos processos sociais, massão e devem ser vistas como “(...) active in the construction and determination of their own social lives, the lives of those around them and of the societies in which they live" (JAMES; PROUT, 1997, p. 08).

Kirsi Pauliina Kallio entende que as crianças podem identificar e compreender os aspectos sociopolíticos, sendo agentes políticos (KALLIO, 2009, p. 05). Seu estudo pauta-se, majoritariamente, na concepção de Sana Nakata, que entende os jovens como indivíduos políticos que atuam nos ambientes privados e públicos (KALLIO, 2009, p. 02). Essa perspectiva é manifestada em um excerto do trabalho de Nakata: "Children are not only political subjects. Sometimes they are political agentes" (NAKATA in KALLIO, 2009, p. 4). Kallio destaca que os jovens podem ser mobilizados pelas ações políticas desenvolvidas por adultos, a partir de suas posições ideológicas (KALLIO, 2009, p. 15).

Patricia C. Gallardo e Alejandra G. Celis asseveram que ser criança é parte de um projeto político de ação e criação, configurando-se na esfera do público e do privado (CASTILLO-GALLARDO; GONZÁLEZCELIS, 2013, p. 119). Tais autoras destacam que a disputa ideológica pela consciência dos jovens, durante o 
regime militar no Chile (1973-1990), era uma batalha cotidiana e aberta. As diferenças na forma “(...) de educar, trasmitir e interpretar la sociedad se constituyó (...) en un espacio (...) en el que la dictadura no iba ganar” (CASTILLO-GALLARDO; GONZÁLEZ-CELIS, 2013, p. 123). Além disso, destacam as dificuldades que os pais tinham em omitir dos meninos e das meninas os acontecimentos da época. Muitos desses jovens, por segurança, deveriam esquecer os nomes de seus pais e de seus familiares e ocultar todas as informações que continham (CASTILLO-GALLARDO; GONZÁLEZ-CELIS, 2013, p. 125-126).

Patricia Castillo, ao analisar a infância durante a ditadura chilena, destaca que as crianças, filhas de militantes políticos, “(...) evalúan la realidad social de la época, demostrando la relevancia que en su juicio de realidad tiene el posicionamiento ideológico de su entorno, los valores sociales en los cuales fueron educados (...)" (CASTILLO-GALLARDO, 2014, p. 02). Considerando os filhos dos militantes como sujeitos políticos, a autora deslinda que a figura de seus pais possui um lugar na memória desse grupo, pois a imagem "paternal" foi fundamental para desqualificar o discurso oficial desenvolvido pelo governo de Augusto Pinochet (CASTILLO-GALLARDO, 2014, p. 07).

Dessa forma, acreditamos que as crianças e os adolescentes que desenvolveram táticas contra a gestão de Alfredo Stroessner no Paraguai foram atores políticos e desempenharam um papel importante na sociedade da época. A seguir, apresentaremos como a fonte expõe o papel político dos jovens durante o stronismo.

\section{A participação política e social das crianças e dos adolescentes durante o governo de Stroessner}

O terceiro e o quinto volume do Informe Final da CVJ têm como escopo a exposição da trajetória dos camponeses, das mulheres, dos povos indígenas e, também, das crianças e dos adolescentes na vida política. O protagonismo infanto-juvenil nas organizações políticosociais contrárias ao regime foi silenciado pela maioria das produções bibliográficas sobre o governo de Stroessner. Esses dois tomos do Informe Final da CVJ romperam com tal hiato, ao apresentarem informações referentes às infrações aos direitos humanos cometidas contra esse grupo e a falta de garantias legais que os protegessem. Tal análise partiu das testemunhas de vítimas adultas que na época em que os delitos foram cometidos possuíam uma idade inferior aos dezoito anos. Atualmente, esses indivíduos vivem com muitas sequelas, oriundas dos momentos traumáticos que vivenciaram (COMISIÓN DE VERDADE Y JUSTICIA, TOMO III, 2008, p. 87-88).

A sociologia da infância afirma que o período infanto-juvenil deve ser explicado e entendido em todos os seus processos. Dessa maneira, cada sociedade produz um determinado modelo infantil, que compreende as relações destes sujeitos com os mecanismos políticos e sociais de uma determinada região. Na história jurídica paraguaia, as primeiras tentativas de garantir direitos constitucionais às crianças e aos adolescentes são encontradas no Código Laboral (Lei $n^{\circ}$ 831/1962). As proteções legais a esses setores são brevemente mencionadas em alguns artigos da Constituição de 1967. Em 1981, foi promulgado o Código del Menor, tornando-se o primeiro princípio infanto-juvenil do país. De acordo com essa lei, a maioridade começava aos vinte anos (COMISIÓN DE VERDADE Y JUSTICIA, TOMO III, 2008, p. 88-89).

O "Ano Internacional da Criança", criado pela Organização das Nações Unidas (ONU) em 1979, foi determinante para desenvolver uma consciência pública sobre a importância de leis que assegurassem os direitos das crianças e dos adolescentes na sociedade para- 
guaia. Em novembro de 1989, a ONU declarou a "Convenção sobre os Direitos da Criança", ratificada pelo Paraguai através da Lei $n^{\circ}$ 57/1990. Tal documento jurídico - juntamente com alguns artigos da Constituição de 1992 - criminalizava todo ato de detenção, tortura, exílio e execução contra os jovens e estabelecia que a maioridade se iniciava aos dezoito anos. Segundo essas Declarações, as crianças dependem diretamente de seus pais - ou de seus familiares - e da comunidade em que estão inseridas (COMISIÓN DE VERDADE Y JUSTICIA, TOMO III, 2008, p. 87-88).

Durante a gestão de Stroessner, os direitos fundamentais desses grupos foram infringidos pelos mecanismos repressores estatais. Em geral, o impacto da violência sofrida pelas crianças e pelos adolescentes naquele período provém de três situações: a) suas experiências traumáticas; b) os impactos em relação à violência exercida contra seus parentes; c) devido a conjuntura específica de cada família que sofria por um familiar torturado, detido ou assassinado (COMISIÓN DE VERDADE Y JUSTICIA, TOMO V, 2008, p. 247249).

Da perspectiva dos direitos desses setores, os anos de 1976 a 1980 correspondem aos tempos mais repressores. Isso se deve ao fato de que, nessa época, o regime passou a reprimir intensivamente as comunidades camponesas no interior do país. Dentre os atores sociais pertencentes à essas organizações estavam as crianças e os adolescentes. Nesse período, foram relatados diversos casos de torturas físicas (golpes, asfixia por imersão em água, dentre outros) e psicológicas (humilhações, ameaças de morte dos pais etc.). Além disso, muitos foram violentados sexualmente (COMISIÓN DE VERDADE Y JUSTICIA, TOMO III, 2008, p. 90). Abaixo, um levantamento das violações aos direitos infanto-juvenis durante a ditadura de Stroessner:

\begin{tabular}{|c|c|c|c|c|c|c|c|}
\hline Idade & Detenção & Tortura & Execução & Desaparecimento & Exílio & Total & $\%$ \\
\hline 1 & 5 & 5 & 0 & 1 & 2 & 13 & $2,3 \%$ \\
\hline 2 & 3 & 2 & 0 & 0 & 0 & 5 & $0,9 \%$ \\
\hline 3 & 1 & 1 & 0 & 0 & 2 & 4 & $0,7 \%$ \\
\hline 4 & 5 & 5 & 0 & 0 & 4 & 14 & $2,4 \%$ \\
\hline 5 & 6 & 6 & 0 & 0 & 0 & 12 & $2,1 \%$ \\
\hline 6 & 7 & 13 & 0 & 0 & 1 & 21 & $3,6 \%$ \\
\hline 7 & 13 & 15 & 0 & 0 & 1 & 29 & $5,0 \%$ \\
\hline 8 & 11 & 16 & 0 & 0 & 3 & 30 & $5,2 \%$ \\
\hline 9 & 13 & 15 & 0 & 0 & 0 & 28 & $4,9 \%$ \\
\hline 10 & 11 & 17 & 0 & 0 & 3 & 31 & $5,4 \%$ \\
\hline 11 & 4 & 9 & 1 & 0 & 0 & 14 & $2,4 \%$ \\
\hline 12 & 17 & 28 & 0 & 0 & 1 & 46 & $8,0 \%$ \\
\hline 13 & 17 & 19 & 0 & 0 & 3 & 39 & $6,8 \%$ \\
\hline 14 & 23 & 27 & 0 & 0 & 3 & 53 & $9,2 \%$ \\
\hline 15 & 24 & 27 & 0 & 0 & 5 & 56 & $9,7 \%$ \\
\hline 16 & 26 & 31 & 0 & 1 & 3 & 61 & $10,6 \%$ \\
\hline 17 & 53 & 53 & 2 & 5 & 8 & 121 & $21,0 \%$ \\
\hline Total & 239 & 289 & 3 & 7 & 39 & 577 & \\
\hline
\end{tabular}

Tabela 1 - Violações às crianças e aos adolescentes. Table 1 - Violations of children and adolescents. Fonte: COMISION DE VERDADE Y JUSTICIA, TOMO III, 2008, p. 93.

Os números apresentados acima não correspondem a todas as vítimas. 
Dos dois mil e cinquenta e nove testemunhos levantados pela equipe da CVJ, aproximadamente $15,7 \%$ equipara-se a indivíduos que eram crianças ou adolescentes no período em que tiveram seus direitos violados. Entre as vítimas dos mecanismos repressivos, $56 \%$ corresponde aos homens e $44 \%$ equivale às mulheres. $\mathrm{O}$ fato de a maior porcentagem proporcionar-se ao sexo masculino é explicado pela seguinte questão: os rapazes, sobretudo os que viviam em comunidades camponesas, eram quem mais acompanhavam os adultos nas atividades de suas organizações. Outra causa pode ser atribuída à dupla inviabilização da participação das mulheres, tanto pelos fatores geracionais, quanto pelas questões de gênero (COMISIÓN DE VERDADE Y JUSTICIA, TOMO III, 2008, p. 92).

De acordo com o documento da CVJ, elas tiveram uma menor participação política e social pelo fato de serem mulheres. Tal afirmação é refutável, haja vista que muitas mulheres desempenharam uma expressiva participação política durante o governo de Stroessner. A respeito de tais distinções de gênero infanto-juvenis, as violações aos direitos masculinos eram associadas ao trabalho forçado, uma vez que as vítimas foram utilizadas como mão-de-obra por parte dos funcionários governamentais, durante as invasões a comunidades camponesas (COMISIÓN DE VERDADE Y JUSTICIA, TOMO V, 2008, p. 258). Tal prática de trabalho forçado era tida como uma forma moderna de escravidão e como algo comum na sociedade paraguaia, já que muitos indivíduos ligados direta ou indiretamente ao Estado utilizaram meninos e meninas como empregados/as (COMISIÓN DE VERDADE Y JUSTICIA, TOMO III, 2008, p. 132).

Já as agressões aos direitos femininos eram relacionadas à violência sexual, como uma maneira de coerção e de domínio do corpo das meninas pelos agressores governamentais (COMISIÓN DE VERDADE Y JUSTICIA, TOMO V, 2008, p. 258). Essas garotas fo- ram estigmatizadas por tal experiência até a idade adulta, uma vez que mantêm os sentimentos de culpa e de vergonha (COMISIÓN DE VERDADE Y JUSTICIA, TOMO III, 2008, p. 93). Muitas jovens foram transformadas em escravas sexuais por funcionários estatais. Meninas de sete a quinze anos eram ludibriadas por militares, que prometiam a seus familiares, geralmente camponeses, uma série de regalias para que entregassem suas filhas. Se negassem cedê-las, eram ameaçados de morte. Também havia pessoas que caçavam moças para vendê-las ou trocá-las por postos públicos (COMISIÓN DE VERDADE Y JUSTICIA, TOMO III, 2008, p. 120-125).

As consequências dessas violações residem em três âmbitos: sociais, psicológicos e físicos. Dentre as sequelas sociais, destacamos a pobreza e a marginalização. Em relação aos desdobramentos psicológicos, oriundos das experiências traumáticas, salientamos a fobia, a depressão, os transtornos de sono e as crises de angústia (COMISIÓN DE VERDADE Y JUSTICIA, TOMO V, 2008, p. 249). Em vários testemunhos existentes nos tomos da $\mathrm{CVJ}$, as vítimas relatam problemas sérios de saúde, causados pelas longas sessões de tortura e/ou pelas agressões sofridas. A maioria dos jovens que tiveram seus direitos violados por pessoas ligadas ao governo ou por instituições estatais formava parte de organizações sociopolíticas. Muitos deles pertenciam a alguma comunidade camponesa. Por fazerem parte dessas associações, o governo considerava-os como adultos e, uma vez sendo membros desses grupos, eram reprimidos (COMISIÓN DE VERDADE Y JUSTICIA, TOMO III, 2008, p. 94-95).

Dessa forma, a violência estatal contra as crianças e os adolescentes foi uma das formas de coibir os agrupamentos sociais que, segundo o regime, estavam contra a ordem e o bem público (COMISIÓN DE VERDADE Y JUSTICIA, TOMO III, 2008, p. 96). As violações cometidas contra esse grupo eram justificadas co- 
mo uma forma dos órgãos repressores localizarem o paradeiro de algum familiar adulto ou para obterem informações sobre algum "subversivo" conhecido. Assim, tais agressões não foram dirigidas especificamente contra eles (COMISIÓN DE VERDADE Y JUSTICIA, TOMO III, 2008, p. 133-135).

Essas violências partiam de uma estratégia de desestruturar o seio familiar e de uma forma de demonstrar o poder governamental, proporcionando um sentimento de terror entre a população e desenvolvendo o imaginário de que todos os grupos ou sujeitos que se colocassem contra a ditadura teriam não só seus direitos violados, mas também o de seus filhos. Nem todos os jovens agredidos pertenciam a uma organização sociopolítica. Muitos foram violados como uma forma de atingir seus pais ou outros familiares. Não obstante, mesmo diante de tal conjuntura, parte deles se opôs às forças autoritárias. Essa resistência atingiu, por diversas vezes, os espaços do privado/cotidiano. Veremos a seguir alguns exemplos dessas experiências renitentes no âmbito privado.

\section{As resistências cotidianas desenvolvidas pelos grupos infanto-juvenis durante o stronismo}

As memórias sobre os impactos psicológicos e físicos da violência contra as crianças e os adolescentes foram apresentadas nos volumes III e V do Informe Final da CVJ. Como ambos se complementam, decidimos analisar os relatos existentes no livro III e, a partir deles, tecer caminhos para a problemática central. Os atos agressivos conduzidos contra os jovens, seja pelos familiares ou pelos agentes estatais, eram cotidianos. Por essa razão, eles não se reconheceram como vítimas diante do sistema repressivo governamental, pois acreditavam que a violência corriqueira era "normal".

Poderíamos associar essa mentalidade com as tradições e os costumes vigentes na época. Os direitos ju- rídicos infanto-juvenis são recentes na história da humanidade. Até o século $\mathrm{XX}$, as crianças não possuíam garantias legais. Aproximando-se da realidade do Paraguai, destacamos a seguinte ocorrência histórica: a convocação de meninos para lutarem na Guerra da Tríplice Aliança (1864-1870). Após sofrer inúmeras baixas, proporcionadas pela força bélica da Tríplice Aliança, o Exército paraguaio não possuía um número considerável de soldados adultos. Diante de tal situação, o Marechal - e também presidente - Francisco Solano López convocou crianças para lutarem contra os combatentes inimigos.

A última grande batalha do conflito, conhecida como Acosta $\tilde{\mathrm{Nu}}$ (1869), contou com milhares de meninos. Ao final, cerca de 3.500 deles foram assassinados pelos soldados brasileiros e argentinos. Por conta dessa experiência, o Paraguai comemora - em 16 de agosto o Día del Niño, em homenagem às crianças que perderam suas vidas nesse episódio bélico. Por não possuírem direitos fundamentais e não terem suas garantias reconhecidas por nenhuma Constituição Nacional, eles sofreram inúmeras violências, tanto no âmbito privado, quanto no espaço público. Assim, as forças repressoras estatais poderiam agir livremente contra os jovens que "infringiam” as leis do país. Com os aparatos jurídicos e constitucionais, ratificados no decorrer da centúria passada, tal situação começou a mudar. Como já informado, durante a gestão de Stroessner diversas crianças foram torturadas, exiladas, assassinadas, detidas, escravizadas e violadas sexualmente por agentes governamentais.

Anacleto Flores Rotela, que em 1980 tinha 14 anos, recorda que foi levado para um órgão estatal e ficou “(...)en el calabozo como dos meses más o menos, en ese tiempo yo no sabía ni los días, nada, me mandan recostar por la pared y me golpeaban por el estómago y por la cabeza (COMISIÓN DE VERDADE Y JUSTI- 
CIA, TOMO III, 2008, p. 109). Outro caso foi o de Albino Rolón Centurión, cuja idade em 1976 era de 13 anos. Ele destaca que o “(...) pegaron con electricidad y (...) después (...) me pegaron y todas las noches nos pateaban por nuestras cabezas diciendo que no debíamos más vivir" (COMISIÓN DE VERDADE Y JUSTICIA, TOMO III, 2008, p. 113). Nesses dois depoimentos é conspícuo a forma de como os órgãos estatais lidavam com as crianças. $\mathrm{O}$ documento não destaca o real motivo dos dois jovens serem torturados.Entretanto, acreditamos que a razão de tal violação reside no fato de que ambos eram filhos de militantes de alguma organização política ou social.

A respeito dos estupros realizados por funcionários governamentais, selecionamos o relato de uma mulher que não se identificou. Ela relembra que em 1976, aos 14 anos, após a intervenção no local onde se encontrava foi dada a:

(...) orden para que los soldados entren en donde yo estaba, y les dije yo a los soldados que tenía una enfermedad grave y contagiosa, mediante eso no me violaron, pero esa noche entró un soldado y a la fuerza me hizo las cosas, me violó, me dio otro lugar para irme en donde había cama y habia sido debajo de la cama ya me estaba esperando un hombre. No sé si era soldado. Seguro que mandaba más, no creo que sea soldado, después de cinco días me soltaron (COMISIÓN DE VERDADE Y JUSTICIA, TOMO III, 2008, p. 121, grifo nosso).

Através desse excerto, notamos que a menina, prevendo o que sucederia, alegou que sofria de uma doença contagiosa, provavelmente uma enfermidade sexualmente transmissível. Tal atitude pode ser considerada como uma tática para não ser violada sexualmente. Não obstante, tal resistência surtiu efeito mo- mentaneamente. Horas mais tarde, foi violentada por um soldado e por um civil que, possivelmente, tinha estritas ligações com o governo. É importante ressaltarmos que a fonte não evidencia se ela possuía ou não tal doença.

Os organismos estatais acreditavam que as crianças e os adolescentes, caracterizados como "subversivos", poderiam ser uma ameaça à ditadura e à sociedade, por proferirem "incitações" ao ódio e intimidar a "paz e o progresso" do país ${ }^{5}$. Isso pode ser observado no relato de Fulgencio Amado Cazal, o qual destaca que em 1968, quando tinha 14, um militar lhe dizia: “( ... 'contá bien nomás, porque te voy a romper los dedos, vos sos comunista ¿verdad?,a estos comunistas hay que matarlos a todos desde pequeños"'(COMISIÓN DE VERDADE Y JUSTICIA, TOMO III, 2008, p. 88). Fulgencio foi ameaçado a ter seus dedos quebrados por conta da posição ideológica de seus pais, pois o regime enquadrava como "comunistas" as atividades dissidentes de militantes políticos e/ou sociais.

A maioria das crianças e dos adolescentes que sofreu algum tipo de violação pertencia direta ou indiretamente a distintas organizações político-sociais, como partidos políticos, sindicatos, associações estudantis e comunidades camponesas. Eles/elas atuavam nesses movimentos a partir da influência e do posicionamento de seus pais. Em Costa Rosado, um grupo de jovens que nos tempos de antanho desempenhava um papel importante em sua comunidade, destacou que os militares, na invasão à colônia em 1980, diziam “(...) que nuestros padres ya estaban muertos, que ellos eran comunistas y por eso nos iban a matar a nosotros también, para cortar de raíz" (COMISIÓN DE VERDADE Y

\footnotetext{
${ }^{5} \mathrm{O}$ discurso oficial do governo de Stroessner era Paz y progreso, pois, em um país que possuía uma instabilidade política e econômica, essa promessa tinha um efeito direto nas camadas mais humildes da população (MORAES, 2000, p.72). Apesar de o discurso oficial ter se propagado entre os setores sociais, isso não inviabilizou as oposições ao regime.
} 
JUSTICIA, TOMO III, 2008, p. 115).

Como citado anteriormente, rememorando tais situações traumáticas, os filhos de militantes, vítimas ou não do processo repressivo, questionavam o sistema político da época e remodelavam suas relações familiares. A memória da figura paternal foi a chave para objetar os discursos realizados pelo governo (CASTILLOGALLARDO; GONZÁLEZ-CELIS, 2015, p. 911). O pai de Gladys Patricia Ortellado foi assassinado em 1976, quando ela tinha 14 anos. Recordando esse episódio, relatou a razão pela qual “(...)no tengo vergüenza de la muerte de mi padre, porque él murió por sus ideales... dijeron que éramos comunistas, le mataron a mi papá, robaron nuestro tractor, robaron toda la plata, robaron nuestras tierras" (COMISIÓN DE VERDADE Y JUSTICIA, TOMO III, 2008, p. 130). Glayds questiona o fato de o regime enquadrar todas as manifestações contrárias como "comunistas". Além disso, os militares usavam desse artifício para assassinar e roubar os indivíduos que possuíam uma ideologia dissonante. É interessante notarmos que, apesar de toda a propaganda anticomunista implementada pela ditadura nas estruturas sociais, ela não tem vergonha do homicídio de seu pai.

O documento da CVJ também discute as diferenciações entre a "cidade" e o "campo". Há no Paraguai uma sensível distinção de cenários, conformada pelas zonas rurais e pela região metropolitana de Assunção (GALEANO, 2010, p. 370-371). É destacado na fonte que a violência exercida no interior e na capital possuía diferentes níveis. Segundo Basilica Espínola, era díspara situação dos camponeses presos“(...)tanto en Asunción como en el interior, a la de los intelectuales o alguna gente de Asunción. Así es, incluso en medio del terror, en la cárcel, había diferencias sociales en el trato de los represores" (COMISIÓN DE VERDADE Y JUSTICIA, TOMO III, 2008, p. 91). Como destaca- do, havia uma diferenciação social, além de geográfica, entre as violações cometidas contra os jovens. De acordó com José Ángel Benítez Estigarribia:

Nosotros, los grupos de estudiantes, fuimos sometidos a unas torturas más leves, porque yo tenía en ese entonces diez $y$ siete años, todos los compañeros estábamos, éramos todos de entre esa edad, éramos garroteados con golpes comunes que te daban los oficiales en ese entonces. Ahora sí, los otros compañeros de las Ligas Agrarias fueron brutalmente torturados con todos los instrumentos que tenían para operar de esa manera (COMISIÓN DE VERDADE Y JUSTICIA, TOMO III, 2008, p. 92, grifo nosso).

O tratamento dos agentes estatais com as vítimas - de qualquer faixa etária - variava a partir de sua localidade. A rede de espionagem desenvolvida pelo governo rompeu com as estruturas de confiança entre os membros das comunidades rurais, pois no campo as relações com os vizinhos e o apoio mútuo é bem maior do que no âmbito urbano. Nas cidades, tal sistema proporcionou uma sensação de desconfiança entre vizinhos e parentes (COMISIÓN DE VERDADE Y JUSTICIA, TOMO V, 2008, p. 20-24). Nas áreas rurais, um dos modus operandi desenvolvido pelas ações repreensivas do regime foi o roubo e o saqueio de casas e terras. Já na zona urbana, o confisco de bens materiais e a perda de trabalhos era uma forma de amedrontamento (COMISIÓN DE VERDADE Y JUSTICIA, TOMO V, 2008, p. 57-60). Dessa forma, percebemos que o setor rural foi o mais afetado pelas estruturas repressoras do Estado autoritário pós-1954.

As violações aos direitos fundamentais das crianças e dos adolescentes eram mais leves se fossem munícipes de grandes cidades, diferentemente da aplicação da agressão estatal contra camponeses que viviam em comunidades camponesas no interior do país. Poderíamos entender tal diferenciação através da mentalidade existente em alguns setores governamentais e 
entre os residentes da capital federal: a ideia de que o interior era composto majoritariamente por pessoas pobres, atrasadas, ignorantes e sem instrução política e educacional. O regime, que possuía um discurso de desenvolvimento e urbanização, mantinha uma empatia maior com os cidadãos pertencentes às grandes cidades.

Entretanto, tal questão pode ser esclarecida por outra perspectiva. Considerando que as colônias comunitárias dos camponeses ofereceram uma resistência ferrenha ao governo, é explicável que os agentes estatais contra-atacariam com uma força bélica destrutiva. É importante ressaltar que as experiências das Ligas Agrarias Cristianas (LAC) foram desbaratadas pelo aparelho repressivo da ditadura. Dentro desse contexto estavam as crianças e os adolescentes que, por participarem dessa organização sociopolítica, foram brutalmente violentadas sexualmente, torturadas e assassinadas pelas forças policiais e militares.

Sendo membros de diferentes associações, as crianças e os adolescentes estavam cientes dos problemas socioeconômicos e políticos do país durante a ditadura. Como afirma Norma Cecilia Franco de Vera:

Las criaturas tenían una niñez sana, yo tenía nueve años, sabía todos los movimientos de la familia, los amigos, lo que ellos hacian, iba a la escuela, los chicos de mi edad trabajábamos en la huerta, teníamos una hora para la huerta, una hora para estudiar, una hora para jugar $y$ sin problemas (COMISION DE VERDADE Y JUSTICIA, TOMO III, 2008, p. 98, grifo nosso).

Apresentando uma opinião semelhante à de Norma, o seguinte depoimento de um sujeito que não quis se identificar, dito na Audiencia Pública sobre Dictadura y Educación, afirma que quando:

(...) niño sentí que tenía seguridad social y económica. (...). Como niños teníamos nuestro espacio de juego, de trabajo y de organización, si las escuelitas campesinas hubieran progresado la historia sería diferente(COMISIÓN DE VERDADE Y JUSTICIA, TOMO III, 2008, p. 98).

A partir desses dois excertos, observamos que as crianças e os adolescentes estavam cientes da conjuntura que o país vivia no período e, através dessa consciência, desenvolveram ações políticas que resistiram às estratégias do governo de Stroessner. É interessante notarmos no depoimento anônimo que as crianças possuíam diferentes espaços próprios: de jogo, de trabalho e de organização. Poderíamos, também, incluir um novo âmbito no cotidiano desses jovens: o campo da resistência. Outra questão que aparece em ambos é o papel das escuelitas campesinas na vida desses jovens.

As LAC criaram um sistema próprio e romperam com as estruturas da escola convencional. As escolinhas camponesas fizeram parte desse projeto de educação alternativo (COMISIÓN DE VERDAD Y JUSTICIA, TOMO V,p. 155-158). O emprego de um modelo distinto ao estipulado pela ditadura e o uso de teóricos marxistas proporcionaram uma reação violenta do regime, que destruiu muitas escolas e utilizou esse espaço para a realização de torturas e assassinatos de camponeses e guerrilheiros, com o intuito de avisar à população que qualquer tipo de atitude opositora ao Estado seria violentamente reprimida por seus agentes.

Conscientes da conjuntura político-econômica paraguaia e sendo membros de um órgão rechaçado pelos aparelhos repressivos do governo, as crianças e os adolescentes desempenharam um posicionamento contrário ao regime, resistindo aos modelos educacionais tradicionais da ditadura. Tal análise pode parecer, à primeira vista, incabível ou truncada, pois o pertencimento deles/delas a tais escolas associar-se-ia a uma decisão de seus pais. Afirmar que tais jovens tinham consciência dos ideais que caracterizavam as escuelitas é uma tarefa dubitável. Não obstante, o fato de serem inte- 
grantes desses locais fez com que se tornassem, aos olhos dos órgãos governamentais, opositores do regime de Stroessner. As sessões de torturas realizadas dentro das escuelitas explicariam a condenação dos agentes estatais pela formação de tais espaços e a repressão ferrenha aos seus membros.

Sobre a violência cometida contra os estudantes dessas escolas alternativas, Marciana Cano relata que, em 1980,quando tinha 11 anos:

\section{(...) nos subieron llevándonos a todos en el chorro, luego nos llevaron ahi en don- de el agua estaba medio estancada y ahi nos sumergieron la cabeza y luego saca- ban de nuevo asi sucesivamente y nos preguntaban otra vez: “¿en dónde está Victoriano Centurión?", y le volvimos a decir de nuevo que no sabíamos nada y nos volvieron a meter en el agua, ahi casi me ahogué, al no decirle nada me solta- ron y le trajo a otra persona, así sucesi- vamente a cada alumno le traían allí $y$ les torturaban (COMISIÓN DE VER- DADE Y JUSTICIA, TOMO III, 2008, p. 91, grifo nosso).}

Esse episódio ocorreu em uma comunidade agrária, na qual agentes militares destruíram a sua escuelita e torturaram os estudantes. Em março de 1980, na região de Caaguazú, um grupo de camponeses "assaltou" um ônibus com a intenção de chegar a Assunção para solicitar às autoridades públicas os títulos de propriedade de seus territórios. Chegando a um determinado trecho, foram atacados por uma força policial que massacrou todos os agricultores. $\mathrm{O}$ único sobrevivente foi Victoriano Centurión. Como resposta a tal episódio, o governo enviou militares para os territórios interioranos com o intuito de saquear e assaltar os agrupamentos camponeses. Podemos notar, a partir do excerto acima, que a busca de Centurión foi um pretexto para violentar os trabalhadores rurais e os seus filhos.

$\mathrm{O}$ interrogatório de crianças e de adolescentes, realizado por policiais e militares, foi um dos aparatos do sistema repressivo estatal que pretendia obter informações sobre o paradeiro de algum familiar adulto ou até mesmo sobre o funcionamento de uma organização política. Essa questão poder ser observada no testemunho de Amandy da Costa González, a qual relata que em:

(...) uno de los interrogatorios de la policía, yo tenía 4 años, recuerdo que me preguntaban de mi padre, no recuerdo muy bien qué es lo que respondía, pero yo cambié mi nombre, decía que mi nombre era Beatriz, entonces, mucho tiempo después pude ver en el 'Archivo del Terror': "los pyragués siguiendo a una niña que se llamaba Beatriz", entonces yo veía: "la niña Beatriz subiéndose a tal colectivo (COMISIÓN DE VERDADE Y JUSTICIA, TOMO III, 2008, p. 134, grifo nosso).

Como exteriorizado anteriormente, durante a ditadura de Pinochet no Chile, muitas crianças tinham que esquecer os nomes de seus pais e familiares como uma forma de segurança. Além disso, deveriam ocultar as conversas e as informações compartilhadas nos espaços privados (CASTILLO-GALLARDO; GONZÁLEZ -CELIS, 2013, p. 126). Essa situação pode ter ocorrido no Paraguai. Como pudemos observar no depoimento acima, em 1976, uma criança de quatro anos, quando interrogada por um agente estatal, mudou o seu nome de batismo, dizendo que se chamava "Beatriz".

Muitos jovens violentados continuaram a ser perseguidos e/ou torturados depois de adultos. A justificativa dada pelos departamentos governamentais era que eles pertenciam a algum órgão político-partidário e/ ou que pensavam diferente do regime. Quando a ditadura terminou e os documentos do Archivo del Terror ${ }^{6}$ foram encontrados e liberados para o público, Amandy se surpreendeu ao perceber que os informantes a associava ao seu codinome. Não é fácil analisarmos claramente seus propósitos ao trocar de nome. Entretanto,

\footnotetext{
${ }^{6}$ Em 22 de dezembro de 1992, Martín Almada encontrou no Departamento de Investigaciones de la Policía milhares de documentos referentes à gestão de Stroessner. O conjunto desses registros foi intitulado como Archivodel Terrore levado ao Palácio da Justiça.
} 
traçaremos alguns caminhos que nos levem a afirmações significativas.

Ao mentir para os funcionários estatais, tal criança pretendia desassociar as acusações geradas contra ela e/ou proteger a identidade de seus familiares. Diante do terror daquele momento e das humilhações vividas, ela desenvolveu uma tática específica ao mudar seu nome. Tal atitude, que mais tarde refletiu nos documentos elaborados pelo regime, constitui-se como uma forma de resistência não "direta" contra as estratégias repressivas. Aproveitando-se das falhas desse sistema, Amandy "jogou" no campo construído por forças externas e logrou com seus objetivos, que naquele momento era escapar com vida. Ela poderia desconhecer tais hiatos, mas estava, naquele instante, resistindo à estratégia governamental. É importante observarmos como essa atitude, consciente ou não, foi responsável pela escapatória da criança e pela proteção de sua identidade.

Antes de encerramos, ressaltamos que nas fontes consultadas existem dezenas de depoimentos que trazem reflexões importantes, como as formas utilizadas pelo governo para violentar o direito infantojuvenil, os impactos físicos e psicológicos na vida das vítimas e as ações políticas e sociais desempenhadas por meninos e meninas. Todavia, o objetivo dos testemunhos não é o de apresentar as maneiras de como os jovens resistiram ao regime, mas ressaltar as violações sofridas por eles e cobrar do Estado Nacional medidas reparatórias. Partindo da ideia de que as memórias traumáticas desse grupo recaíram sobre o aspecto do privado e que os entrevistados trouxeram à tona suas participações políticas durante o stronismo, selecionamos nesse artigo alguns excertos que nos ajudaram a entender as maneiras de como os meninos e as meninas resistiram ao Estado autoritário pós-1954. A inclusão desses depoimentos auxilia a constituição de uma memória coletiva que entenda que tais violações não eram "normais", tampouco medidas exemplificadoras. Ao contrário,eram ações violentas que serviram para repreender as atividades políticas desses jovens.

\section{Considerações finais}

Grande parte das produções bibliográficas sobre o governo do General Stroessner silencia a atuação política da população, além de não apresentar a resistência desempenhada por tal setor. O sentimento de medo, o sistema assistencialista e os mecanismos desenvolvidos pela ditadura são tidos, pela maioria dos autores, como formas que desarticularam politicamente os grupos sociais e que desenvolveram um apoio incondicional ao regime. Tanto os estudos sobre o stronismo, quanto a fonte analisada, não problematizam o sentimento de terror. Nesses materiais, o temor é sempre justificável como um sentimento que desarticulou as ações opositoras da sociedade. Diferentemente dessa visão, o presente artigo demonstrou como as atuações das crianças e dos jovens foram reconfiguradas pelo medo. Indicamos que existiram apropriações do amedrontamento social, como mostra o depoimento de Amandy da Costa González.

Essa discussão existente na bibliografia pode ser observada - ainda que de forma indireta - nos tomos do Informe Final da CVJ. Entretanto, o propósito desse documento foi a introdução dos testemunhos das vítimas diretas e indiretas dos aparelhos repressivos desempenhados pelos órgãos estatais. A memória referente à ditadura cívico-militar de Stroessner, ao menos as destacadas no tomo III do Informe Final da CVJ, deixou de ser associada ao desenvolvimento políticoeconômico e passou a ser associada às violações aos direitos humanos. Sendo assim, tal fonte questiona a história oficial, construída por forças políticoideológicas de certos grupos que estavam no poder, e apresenta uma nova perspectiva sobre o passado stronista. 


\section{Fonte}

COMISIÓN DE VERDAD Y JUSTICIA. Informe final: Las violaciones de derechos de algunos grupos en situación de vulnerabilidad y riesgo (tomo III). Asunción: CVJ, 2008.

COMISIÓN DE VERDAD Y JUSTICIA. Informe final: Las Secuelas de las Violaciones de Derechos Humanos La Experiencia de las Víctimas (tomo V). Asunción: CVJ, 2008.

Referências bibliográficas

ARDITI, Benjamín. Adíos a Stroessner. La Reconstrucción de la política en el Paraguay. Asunción: Centro de Documentación y Estudios (CDE), 1992.

BENJAMIN, Walter. Canteiro de obra. In: Obras escolhidas II. Tradução: Rubens Rodrigues Torres Filho; José Carlos Martins Barbosa. São Paulo: Editora Brasiliense, 1987, p. 18-19.

BERGER, Peter L; LUCKMANN, Thomas. A construção social da realidade. Um livro sobre a sociologia do conhecimento. Tradução: Ernesto de Carvalho. Lisboa: Dinalivro, 2004.

CASTILLO-GALLARDO, Patricia; GONZÁLEZ-CELIS, Alejandra. Infancia, dictadura yresistencia: hijos e hijas de la izquierda chilena (1973-1989). Revista Latinoamericana de Ciencias Sociales, Niñez y Juventud, 13, 2015, p. 907-921.

. Niñez en dictadura: historia, psicoanálisis y memoria. A propósito de un ejercicio arqueológico de la niñez en la Dictadura Chilena. Anais do XXX Congreso de la Federación Psicoanalítica de América Latina, "Realidades y Ficciones". Buenos Aires: 2014, p. 01-12.

; GONZÁLEZ-CELIS, Alejandra González. Niñez en dictadura: Lo filiativo como espacio de resistencia. Revista de Geografía Espacios, Vol. 3, N. 6, 2013, p. 117-131.

CERTEAU, Michel de. A invenção do cotidiano: 1, Artes de fazer. Tradução: Ephraim Ferreira Alves. Petrópolis: Vozes, 1998.

GALEANO, Luis A. "Los campesinos y la lucha por la tierra". In: TELESCA, Ignacio (org.). Historia del Paraguay. Asunción: Taurus, 2010, p. 357-374.

GAUTO, Dionisio; TALAVERA, Raquel. Signo de esperanza de lograr la reparación: la Comisión de Verdad y Justicia. Derechos Humanos en Paraguay 2003. Asunción: CODEHUPY, Coordinadora de Derechos Humanos del Paraguay, 2003, p. 79-92.

JAMES, Allison; PROUT, Alan. A New Paradigm for the Sociology of Childhood? Provenance, Promise and Problems. In:__(ed.). Constructing and reconstructing childhood: Contemporary issues in the sociological study of childhood. London; Washington, D.C.: Falmer Press, 1997, p. 07-33.

KALLIO, Kirsi Pauliina. Between social and political: children as political selves. Childhoods Today, Volume 3, 2009, p. 01-22.

MORAES, Ceres. Paraguai, a consolidação de Stroessner 1954-1963. Porto Alegre: Edipuc-RS, 2000.

PEÑA OCHOA, Monica; CHAVEZ IBARRA, Paulina; VERGARA DEL SOLAR, Ana. Los niños como agentes políticos: tácticas cotidianas de resistencia en niñas chilenas de estrato socioeconómico medio. Sociedade e Cultura, v. 17, núm. 2, 2014, p. 291-300.

PEREIRA JÚNIOR, Paulo Alves. Política, silenciamento e representações: os setores populares na historiografia sobre o regime stronista. In: Revista Eletrônica da ANPHLAC: v. 18, 2015, p. 23-55.

SOTO, Clyde; BARREIRO, Line Barreiro; RIQUELME, Quintín; VILLALBA, Roberto Sociedad civil y construcción democrática em Paraguay. Experiencias de participación e incidencia de los movimientos sociales. In: ALBUQUERQUE, Maria do Carmo (Org.) La construcción democrática desde abajo en el Cono Sur. San Pablo: Instituto Polis, 2004, p. 135-193. 